\title{
Cancer Stem Cell-Exosomes, Unexposed Player in Tumorigenicity
}

\author{
Batla S. Al-Sowayan ", Alaa T. Al-Shareeda and Bahauddeen M. Alrfaei \\ Stem Cells and Regenerative Medicine Unit, Cell Therapy \& Cancer Research Department, King Abdullah International \\ Medical Research Center/King Saud Bin Abdulaziz University for Health Sciences, Ministry of National Guard Health Affairs, \\ Riyadh, Saudi Arabia
}

Keywords: cancer stem cell (CSC), exosome, cancer, cancer cell-derived exosomes, stem cell

\section{INTRODUCTION}

Cancer is a well-known, yet poorly understood disease. In which, a healthy tissue is morphed into a cancerous tissue through an intricate, multistep process. This polymorphism has been the focus of cancer research for many decades. Scientists have agreed on a set of traits that are thought to be shared by all cancer tissue types, these traits include; enabling proliferation, evading growth

\section{OPEN ACCESS}

Edited by:

Rebecca Lim

Hudson Institute of Medical Research,

Australia

Reviewed by:

Sonia A. Melo,

University of Porto, Portugal

Zui Pan,

University of Texas at Arlington,

United States

*Correspondence:

Batla S. Al-Sowayan

alsowayanba@ngha.med.sa

Specialty section:

This article was submitted to Translational Pharmacology,

a section of the journal

Frontiers in Pharmacology

Received: 21 November 2019

Accepted: 12 March 2020

Published: 30 March 2020

Citation:

Al-Sowayan BS, Al-Shareeda AT and Alrfaei BM (2020) Cancer Stem

Cell-Exosomes, Unexposed

Player in Tumorigenicity.

Front. Pharmacol. 11:384.

doi: 10.3389/fphar.2020.00384 suppressors, resisting cell death, replicative immortality, inducing angiogenesis, and initiating invasion and metastasis, along with other enabling characteristics (Hanahan and Weinberg, 2000; Hanahan and Weinberg, 2011). As researchers investigate the development and propagation of these traits, or as they are called the "hallmarks" of cancer, it became evident that cancer cell-derived extracellular vesicles (EVs), particularly exosomes, play a major role in almost all of them.

In the late 1940s, it was recognized that cells release spherical shaped particles called EVs (Chargaff and West, 1946). Then, almost 40 years later, "exosomes" were acknowledge as a distinct sub-type of EVs (Trams et al., 1981). Up tell now, it is technically challenging to obtain a pure fraction of a specific EV sub-type, due to similarities shared amongst these vesicles. However, the International Society for Extracellular Vesicles, have released a position statement on the minimal experimental requirements for definition of EVs and their functions (MISEV2014; updated in 2018; MISEV2018) (Lotvall et al., 2014; Théry et al., 2018). The MISEV distinction between the different EV sub-types realize on size, density, morphology, subcellular origin, and composition. This was done in order to make scientific reporting on EV biology more consistent and reliable. Most published literature on EVs, including the literature on the role of EVs in cancer, use the term "exosomes" to refer to the EV sub-type under study. These studies include a section that describes the method of "exosome" isolation, and at least a couple of characterization techniques, to justify their nomenclature. Characterization of exosomes in published literature is often based on size and "exosome-enriched" proteins content verification.

On the other hand, the concept of "cancer stem cell" (CSC) only emerged in the 1990s (Lapidot et al., 1994), with a lot of controversy and a number of proposed theories following it. Some say that CSC arise as a result of normal stem cell mutation, while others suggests that CSC arise as a result of a somatic cell acquiring erroneous stem cell characteristics, turning it into cancerous stem cell that can differentiate into heterogeneous population of cancer cells (Baccelli and Trumpp, 2012).

Abbreviations: EV, Extracellular Vesicle; CSC, Cancer Stem Cell; MVBs, Multivesicular Bodies; miRNA, micro Ribonucleic Acid; mRNA, messenger Ribonucleic Acid; EMT, Epithelial-Mesenchymal Transition; BMMSC, Bone-Marrow Mesenchymal Stem Cell; CD, Clusters of Differentiation; VEGF, Vascular Endothelial Growth Factor; STAT3; Signal Transducer and Activator of Transcription-3; IL, Interleukin. 
Nevertheless, CSCs are now recognized as distinct population of cancer cells, and the CSC-model, is accepted as one of the two most popular models of cancer. The other model being the "clonal evolution-model", which was described earlier in 1970s. It was postulated that cancer results from the accumulation of mutations in a given group of somatic cell population, within a tissue, thus given raise to heterogeneous population of cancer cells (Nowell, 1976). As the CSC-model becomes more popular, the role of CSCs, as a sub-type of cancer cells, within the tumor microenvironment has recently come to light, especially with advances in stem cell research during the last couple of decades. However, the role of CSC-exosomes, as a sub-type of cancer exosomes, is still under the shadow. Thus, in this article we aim to provide a standpoint on the possible role of CSC-exosomes, and why it should be examined as a separate group of cancer cellexosomes, based on published literature.

\section{Exosomes, Devoted Messengers for Good or Bad}

Exosomes originate from the inward budding of the early endosomes, which later mature into multivesicular bodies (MVBs) (Doyle and Wang, 2019). Depending on their content, MVBs are either sent to the lysosome to be degraded or released into the extracellular space, forming what's called exosomes (Doyle and Wang, 2019). Cells of different tissue types were found to release exosomes in order to facilitate intercellular communication, thus initiating different biological actions (Ma et al., 2019). Cancer cells, and cancer-associated cells, within the tumor micro-environment were also found to release exosomes. This allows them to commute their message to malignant and non-malignant cells, and initiate pathways that support tumor survival and propagation (Wortzel et al., 2019). The exosome mediated intercellular communication is enabled through "exosomal cargo". This includes functional proteins, microribonucleic acid (miRNAs) and messenger RNAs (mRNAs) (Hessvik and Llorente, 2018). Exosomes will deliver its cargo from the releasing cell into the recipient cell, which contains the encrypted message. There is a growing body of published literature on the role of cancer cell-exosomes in promoting cancer progression through enabling recipient cells to acquire the mentioned "hall marks" of cancer. A number of studies, have repeatedly shown that cancer cell-exosomes, of different cancer types, significantly increase cancer cell proliferation and inhibit apoptosis by activating various proposed cellular pathways (Zhang et al., 2018; Qian et al., 2019). Studies have also shown that cancer cell-exosomes stimulate angiogenesis by stimulating endothelial cells viability, migration, and tube formation via the transfer of pro-angiogenic proteins and miRNAs (Yi et al., 2015; Bao et al., 2018; Lin et al., 2018; Yukawa et al., 2018). Likewise, it was reported that cancer cell-exosomes induce replicative immortality via the transfer of telomerase reverse transcriptase mRNA from the telomerase activate cancer cell to the telomerase silenced somatic cell (Gutkin et al., 2016). As for metastasis, it is projected that cancer cells induce metastasis by packing its exosomes with promoters of the epithelial-mesenchymal transition (EMT) cascade, to initiate EMT in the neoplastic epithelial cells, within the tumor microenvironment (Webber et al., 2015; Rahman et al., 2016; Xiao et al., 2016). It is also projected that cancer cells will establish a "pre-metastatic" niche through its exosomes. Cancer cells will release its exosomes into the circulation, where they travel to the metastasis site (CostaSilva et al., 2015; Liu et al., 2016; Syn et al., 2016). There, cancer cell-exosomes will up-regulate the pro-inflammatory molecules, and vascular leakiness, to mobilize cells that constitute the premetastatic niche (Costa-Silva et al., 2015; Liu et al., 2016; Syn et al., 2016). Finally, it is projected that while traveling through the circulation, and engraftment into the new tissue, cancer cellexosomes support cancer cells by allowing them to escape immune surveillance (Mrizak et al., 2015; Muller et al., 2016; Song et al., 2016). Moreover, in addition to the classical hall marks of cancer, it was reported by a recent study that prostate cancer cell-exosomes play a role in transforming local prostate tissue stem cells into CSCs (Ngalame et al., 2018). While another study reported that glioma cell-exosomes induced a "tumor-like" phenotype in bone-marrow mesenchymal stem cells (BMMSCs) (Ma et al., 2019). This was reported to be based on increased proliferation, migration, and invasion rates of treated BMMSCs. In addition to alteration in BMMSCs protein production, including the production of the metastasis-related proteins.

\section{Cancer Stem Cell, the Black Sheep of the Stem Cell Family}

CSCs are cancer cells (found within tumors) that possess characteristics associated with normal stem cells, specifically self-renewal and the ability to differentiate and give rise to different cell types found in a particular cancer specimen i.e. CSCs are tumor-forming cells (Sun et al., 2018). CSCs can be identified by using a set of unified surface markers (i.e. clusters of differentiation (CD); CD44, CD24, CD133), in addition to added tissue specific markers depending on cancer type (Phi et al., 2018). Within the tumor microenvironment, the CSCs are rear and reside in highly specialized niches (Sreepadmanabh and Toley, 2018). The CSCs niche is designed to maintain and protect the CSCs, allowing them to resist many current anticancer treatments (Prieto-Vila et al., 2017). The CSCs niche will also allow the cells to stay dormant for long periods of time, before initiating local recurrent and/or distant metastatic tumors (Plaks et al., 2015). Thus, it is hypothesized that targeting the whole tumor will only slow down tumor expansion while targeting the CSCs, in particular, will jeopardize tumor growth (Garcia-Mayea et al., 2019). At the same time, in regenerative medicine research, it was reported that stem cells and progenitor cells exert their tissue regeneration effects through the release of paracrine factors, mainly exosomes. Studies are consistently showing that injecting the cell-derived exosomes alone, is enough to induce the same regenerative effect as the "whole-cell" transplant approach. For example, it was reported that exosomes derived from embryonic stem cells (Khan et al., 2015), BMMSCs (Zou et al., 2019), and cardiac progenitor cells (Kervadec et al., 2016), all mimic the benefits of injecting their parent cells in a chronic heart failure and myocardial infarction animal models. Thus, it is logical to assume that CSCs function through the same 
mechanism as other cancer cells and non-cancer stem cells. We can project that CSCs fulfill its "stemness duties" through the release of paracrine factors, with exosomes as a key player.

\section{What Is Proposed?}

As discussed above, cancer cell-exosomes are crucial for tumor initiation, maintenance, and propagation. However, published literature on this subject matter often don't describe the subtype of cancer cells that these exosomes were derived from. It is well established by now that cancer cell-exosomes mediate cell to cell communication within the tumor microenvironment, to support and promote tumorigenesis. It is also well established by now that any alteration to parent cell, alters exosome secretion and content, which in turn alters its message. For example, when cancer cells were subjected to hypoxia prior to exosome isolation, to reflect the tumor's hypoxic environment, these exosomes significantly increased migration and invasion of cancer cells ( $\mathrm{Li}$ et al., 2016), and tube formation by endothelia cells (Kucharzewska et al., 2013; Hsu et al., 2017), compared with exosomes derived from normoxic cancer cells. Therefore, it could be hypothesized that the sub-population of cancer cells, CSCs, produce exosomes with unique characteristics, and thus functions. Currently, there are only few reports on "CSC-derived exosomes", and their role in cancer propagation, compared to "non-stem cancer cell-derived exosomes" (Table 1). One of the first studies to address this issue reported that the "macrovesicles" that had the in vitro and in vivo angiogenic effect, in renal cancer, were those driven from the $\mathrm{CD} 105^{+}$cancer cell sub-population (Grange et al., 2011). Then later on, one study did a miRNA content comparison, and reported that prostate CSC-derived exosomes have in fact a different miRNA content compared with non-stem prostate cancer cell-derived exosomes (Sánchez et al., 2016). Then, a following study reported that glioma stem cell-derived exosomes promoted angiogenesis by containing a particularly high levels of miRNA-21, which upregulates the vascular endothelial growth factor (VEGF) (Sun et al., 2017). While another study identified 11 miRNAs that are characteristic of gastric CSC-derived exosomes, and suggested that a measurement of these miRNAs in patient serum could be used as a predictor of cancer metastasis (Sun et al., 2017). Other recent CSC-exosomes investigations focusing on their role in metastasis, reported that CSC-derived exosomes promote metastasis by promoting EMT in renal cell carcinoma (Wang et al., 2019) and thyroid cancer (Hardin et al., 2018) via the transfer of miRNA-19b-3p and non-coding-RNAs respectively. Whereas other reported on CSC-exosome role in creating a protumoral microenvironment. For example, it was reported that glioblastoma stem cell-derived exosomes direct monocytes toward the immune suppressive "M2" phenotype, through the signal transducer and activator of transcription-3 (STAT3) pathway, creating an immunosuppressive microenvironment (Gabrusiewicz et al., 2018). While colorectal cancer stem cellderived exosomes promote a pro-tumoral phenotype in neutrophils by increasing interleukin-(IL)-1 $\beta$ expression (Hwang et al., 2019)

Since tumor-host cross-talk is believed to be initiated by CSCs, and communication between cancer cells and other cells is conducted through exosomes, it's of great importance to take a closer look at the role of CSCs-exosomes, and its involvement in

TABLE 1 | Summary of published work on the distinct role of CSC-derived exosomes in tumorigenicity.

\begin{tabular}{|c|c|c|c|}
\hline Exosome population & Tumorigenic action & Proposed mechanism of action & Reference \\
\hline $\begin{array}{l}\text { Macrovesicles derived from } \\
\text { CD105+ cells of renal } \\
\text { carcinoma specimens }\end{array}$ & $\begin{array}{l}\text { Promoted angiogenesis } \\
\text { and metastasis both in } \\
\text { vitro and in vivo }\end{array}$ & $\begin{array}{l}\text { miRNA screening showed } 24 \text { upregulated, and } 33 \text { downregulated miRNAs in } \\
\text { CD105 } 5^{+} \text {macrovesicles compared to CD } 105^{-} \text {macrovesicles. This distinct } \\
\text { miRNA composition favor tumor growth and invasion. }\end{array}$ & (Grange et al., 2011) \\
\hline $\begin{array}{l}\text { Exosomes derived from } \\
\text { CD133+ cells of glioblastoma } \\
\text { cell line }\end{array}$ & $\begin{array}{l}\text { Increased the in vitro } \\
\text { angiogenic capacity of } \\
\text { endothelial cells }\end{array}$ & $\begin{array}{l}\text { miRNA analysis revealed elevated levels of miRNA- } 21 \text { in the CD133+ cells, } \\
\text { hypothesizing that the derived exosomes promoted angiogenesis through the } \\
\text { miRNA-21NEGF pathway. }\end{array}$ & (Sun et al., 2017) \\
\hline $\begin{array}{l}\text { Exosomes derived from } \\
\text { CD105+ cells of clear cell renal } \\
\text { cell carcinoma specimens }\end{array}$ & $\begin{array}{l}\text { Induced EMT of cancer } \\
\text { cells in vitro, and } \\
\text { promoted metastasis in } \\
\text { vivo }\end{array}$ & $\begin{array}{l}\text { miRNA analysis revealed elevated levels of miRNA-19b-3p in the CD105+ } \\
\text { cell-derived exosomes. This in turn affected the protein levels of PTEN, a key } \\
\text { mediator of cell migration. }\end{array}$ & (Wang et al., 2019) \\
\hline $\begin{array}{l}\text { Exosomes derived from } \\
\text { spheroid formations of thyroid } \\
\text { cancer cell lines }\end{array}$ & $\begin{array}{l}\text { Induced in vitro EMT in } \\
\text { normal and non- } \\
\text { cancerous thyroid cells }\end{array}$ & $\begin{array}{l}\text { miRNA analysis revealed elevated levels of MALTA1, EMT marker SLUG and } \\
\text { stem cell marker SOX2, in exosome treated cells. }\end{array}$ & (Hardin et al., 2018) \\
\hline $\begin{array}{l}\text { Exosomes derived from } \\
\text { glioblastoma } \\
\text { cell lines cells cultured in stem } \\
\text { cell-permissive medium }\end{array}$ & $\begin{array}{l}\text { Polarized monocytes into } \\
\text { M2 macrophage } \\
\text { phenotype }\end{array}$ & $\begin{array}{l}\text { Western Blot analysis revealed up regulation of PD-L1 in exosome-treated } \\
\text { monocytes. PD-L1 correlates with increased STAT3 pathway } \\
\text { phosphorylation, which mediate this immune suppressive switch. }\end{array}$ & (Gabrusiewicz et al., 2018) \\
\hline $\begin{array}{l}\text { Exosomes derived from } \\
\text { spheroid formations of } \\
\text { colorectal cancer cell line }\end{array}$ & $\begin{array}{l}\text { Prompted a pro-tumoral } \\
\text { phenotype in neutrophils }\end{array}$ & $\begin{array}{l}\text { miRNA and ELISA analysis revealed elevated levels of IL-1 } \beta \text { in exosome- } \\
\text { treated neutrophils and their condition medium. }\end{array}$ & (Hwang et al., 2019) \\
\hline
\end{tabular}


tumor aggressiveness. Also, to examine their miRNA content, compared to non-stem cancer cell- exosomes, in order to postulate mechanisms of actions. Then finally, develop a cancer management strategy that targets CSCs, and involves blockage of the CSC-exosome release channels.

\section{DISCUSSION}

CSCs generate tumors through the stem cell processes of selfrenewal and differentiation into multiple malignant cell types. Based on advances in cell signaling biology, it's expected that these CSCs function through its exosomes. The term "exosome" was used in this article due to the fact that published literature describing EVs role in cancer often refer to the EV sub-type being examined as exosomes. These publications offer reasonable evidence that the EV sub-type being examined is in fact exosomes, via various methods of characterization. Other sub-types of EVs i.e. ectosomes,

\section{REFERENCES}

Baccelli, I., and Trumpp, A. (2012). The evolving concept of cancer and metastasis stem cells. J. Cell Biol. 198 (3), 281-293. doi: 10.1083/jcb.201202014

Bao, L., You, B. O., Shi, S. I., Shan, Y., Zhang, Q., Yue, H., et al. (2018). Metastasisassociated miR-23a from nasopharyngeal carcinoma-derived exosomes mediates angiogenesis by repressing a novel target gene TSGA10. Oncogene 37 (21), 2873-2889. doi: 10.1038/s41388-018-0183-6

Chargaff, E., and West, R. (1946). The biological significance of the thromboplastic protein of blood. J. Biol. Chem. 166 (1), 189-197.

Costa-Silva, B., Aiello, N. M., Ocean, A. J., Singh, S., Zhang, H., Thakur, B. K., et al. (2015). Pancreatic cancer exosomes initiate pre-metastatic niche formation in the liver. Nat. Cell Biol. 17 (6), 816-826. doi: 10.1038/ncb3169

Doyle, L. M., and Wang, M. Z. (2019). Overview of Extracellular Vesicles, Their Origin, Composition, Purpose, and Methods for Exosome Isolation and Analysis. Cells 8 (7), 727. doi: 10.3390/cells8070727

Gabrusiewicz, K., Li, X., Wei, J., Hashimoto, Y., Marisetty, A. L., Ott, M., et al. (2018). Glioblastoma stem cell-derived exosomes induce M2 macrophages and PD-L1 expression on human monocytes. Oncoimmunology 7 (4), e1412909. doi: 10.1080/2162402X.2017.1412909

Garcia-Mayea, Y., Aiello, N. M., Ocean, A. J., Singh, S., Zhang, H., Thakur, B. K., et al. (2019). Insights into new mechanisms and models of cancer stem cell multidrug resistance. Semin. Cancer Biol.

Grange, C., Tapparo, M., Collino, F., Vitillo, L., Damasco, C., Deregibus, M. C., et al. (2011). Microvesicles released from human renal cancer stem cells stimulate angiogenesis and formation of lung premetastatic niche. Cancer Res. 71 (15), 5346-5356. doi: 10.1158/0008-5472.CAN-11-0241

Gutkin, A., Uziel, O., Beery, E., Nordenberg, J., Pinchasi, M., Goldvaser, H., et al. (2016). Tumor cells derived exosomes contain hTERT mRNA and transform nonmalignant fibroblasts into telomerase positive cells. Oncotarget 7 (37), 59173-59188. doi: 10.18632/oncotarget.10384

Hanahan, D., and Weinberg, R. A. (2000). The hallmarks of cancer. Cell 100 (1), 57-70. doi: 10.1016/S0092-8674(00)81683-9

Hanahan, D., and Weinberg, R. A. (2011). Hallmarks of cancer: the next generation. Cell 144 (5), 646-674. doi: 10.1016/j.cell.2011.02.013

Hardin, H., Helein, H., Meyer, K., Robertson, S., Zhang, R., Zhong, W., et al. (2018). Thyroid cancer stem-like cell exosomes: regulation of EMT via transfer of lncRNAs. Lab. Invest. 98 (9), 1133-1142. doi: 10.1038/s41374-018-0065-0

Hessvik, N. P., and Llorente, A. (2018). Current knowledge on exosome biogenesis and release. Cell Mol. Life Sci. 75 (2), 193-208. doi: 10.1007/s00018-017-2595-9

Hsu, Y. L., Hung, J. Y., Chang, W. A., Lin, Y. S., Pan, Y. C., Tsai, P. H., et al. (2017). Hypoxic lung cancer-secreted exosomal miR-23a increased angiogenesis and microvesicle particles, and apoptotic bodies, could be released by cancer cells/CSCs, and could play a role as well. However there is no adequate reporting on this in the literature. Therefore, based on findings on the role of cancer cell- exosomes, and the role of CSCs in cancer, the role of "CSC-exosomes" should be investigated as a separate entity. Such studies will encounter a significant technical and quality control issues related to harvestation of a pure CSC population, and subsequent yield of pure CSC-exosome fraction. Nevertheless, the knowledge provided by these studies will be crucial in developing a more effective approaches to control progression and metastasis of tumors and prevent recurrence.

\section{AUTHOR CONTRIBUTIONS}

BA-S conceptualized and wrote the article. Other authors were involved in manuscript review and editing.

vascular permeability by targeting prolyl hydroxylase and tight junction protein ZO-1. Oncogene 36 (34), 4929-4942. doi: 10.1038/onc.2017.105

Hwang, W. L., Lan, H. Y., Cheng, W. C., Huang, S. C., and Yang, M. H. (2019). Tumor stem-like cell-derived exosomal RNAs prime neutrophils for facilitating tumorigenesis of colon cancer. J. Hematol. Oncol. 12 (1), 10. doi: 10.1186/s13045-019-0699-4

Kervadec, A., Bellamy, V, El Harane, N., Arakéan, L., Vanneaux, V., Cacciapuoti, I., et al. (2016). Cardiovascular progenitor-derived extracellular vesicles recapitulate the beneficial effects of their parent cells in the treatment of chronic heart failure. J. Heart Lung Transplant. 35 (6), 795-807. doi: 10.1016/j.healun.2016.01.013

Khan, M., Nickoloff, E., Abramova, T., Johnson, J., Verma, S. K., Krishnamurthy, P., et al. (2015). Embryonic stem cell-derived exosomes promote endogenous repair mechanisms and enhance cardiac function following myocardial infarction. Circ. Res. 117 (1), 52-64. doi: 10.1161/CIRCRESAHA.117.305990

Kucharzewska, P., Christianson, H. C., Welch, J. E., Svensson, K. J., Fredlund, E., Ringn, M., et al. (2013). Exosomes reflect the hypoxic status of glioma cells and mediate hypoxia-dependent activation of vascular cells during tumor development. Proc. Natl. Acad. Sci. U S A 110 (18), 7312-7317. doi: 10.1073/ pnas. 1220998110

Lapidot, T., Sirard, C., Vormoor, J., Murdoch, B., Hoang, T., Caceres-Cortes, J., et al. (1994). A cell initiating human acute myeloid leukaemia after transplantation into SCID mice. Nature 367 (6464), 645-648. doi: 10.1038/367645a0

Li, L., Li, C., Wang, S., Wang, Z., Jiang, J., Wang, W., et al. (2016). Exosomes Derived from Hypoxic Oral Squamous Cell Carcinoma Cells Deliver miR-21 to Normoxic Cells to Elicit a Prometastatic Phenotype. Cancer Res. 76 (7), 17701780. doi: 10.1158/0008-5472.CAN-15-1625

Lin, X. J., Fang, J. H., Yang, X. J., Zhang, C., Yuan, Y., Zheng, L., et al. (2018). Hepatocellular Carcinoma Cell-Secreted Exosomal MicroRNA-210 Promotes Angiogenesis In Vitro and In Vivo. Mol. Ther. Nucleic Acids 11, 243-252. doi: 10.1016/j.omtn.2018.02.014

Liu, Y., Gu, Y., Han, Y., Zhang, Q., Jiang, Z., Zhang, X., et al. (2016). Tumor Exosomal RNAs Promote Lung Pre-metastatic Niche Formation by Activating Alveolar Epithelial TLR3 to Recruit Neutrophils. Cancer Cell 30 (2), 243-256. doi: 10.1016/j.ccell.2016.06.021

Lötvall, J., Hill, A. F., and Hochberg, F. (2014). Minimal experimental requirements for definition of extracellular vesicles and their functions: a position statement from the International Society for Extracellular Vesicles. J. Extracell Vesicles 3, 26913. doi: 10.3402/jev.v3.26913

Ma, Z., Cui, X., Lu, L., Chen, G., Yang, Y., Hu, Y., et al. (2019). Exosomes from glioma cells induce a tumor-like phenotype in mesenchymal stem cells by activating glycolysis. Stem Cell Res. Ther. 10 (1), 60. doi: 10.1186/s13287-0191149-5 
Mrizak, D., Martin, N., Barjon, C., Jimenez-Pailhes, A. S., Mustapha, R., Niki, T., et al. (2015). Effect of nasopharyngeal carcinoma-derived exosomes on human regulatory T cells. J. Natl. Cancer Inst 107 (1), 363. doi: 10.1093/jnci/dju363

Muller, L., Mitsuhashi, M., Simms, P., William, E. G., and Whiteside, T. L. (2016). Tumor-derived exosomes regulate expression of immune function-related genes in human T cell subsets. Sci. Rep. 6, 20254. doi: 10.1038/srep20254

Ngalame, N. N., Luz, A.L., Makia, N., and Tokar, E. J. (2018). Arsenic Alters Exosome Quantity and Cargo to Mediate Stem Cell Recruitment Into a Cancer Stem CellLike Phenotype. Toxicol. Sci. 165 (1), 40-49. doi: 10.1093/toxsci/kfy176

Nowell, P. C. (1976). The clonal evolution of tumor cell populations. Science 194 (4260), 23-28. doi: 10.1126/science.959840

Phi, L. T., Sari, I. N., Yang, Y. G., Lee, S. H., Jun, N., Kim, K. S., et al. (2018). Cancer Stem Cells (CSCs) in Drug Resistance and their Therapeutic Implications in Cancer Treatment. Stem Cells Int. 2018, 5416923. doi: 10.1155/2018/5416923

Plaks, V., Kong, N., and Werb, Z. (2015). The cancer stem cell niche: how essential is the niche in regulating stemness of tumor cells? Cell Stem Cell 16 (3), 225238. doi: 10.1016/j.stem.2015.02.015

Prieto-Vila, M., Takahashi, R. U., Usuba, W., Kohama, I., and Ochiya, T. (2017). Drug Resistance Driven by Cancer Stem Cells and Their Niche. Int. J. Mol. Sci. 18 (12), 2574. doi: 10.3390/ijms18122574

Qian, S., Tan, X., Liu, X., Liu, P., and Wu, Y. (2019). Exosomal Tenascin-c induces proliferation and invasion of pancreatic cancer cells by WNT signaling. Onco Targets Ther. 12, 3197-3205. doi: 10.2147/OTT.S192218

Rahman, M. A., Barger, J. F., Lovat, F., Gao, M., Otterson, G. A., Nana-Sinkam, P., et al. (2016). Lung cancer exosomes as drivers of epithelial mesenchymal transition. Oncotarget 7 (34), 54852-54866. doi: 10.18632/oncotarget.10243

Sanchez, C. A., Andahur, E. I., Valenzuela, R., Castellón, E. A., Fullá, J. A., Ramos, C. G., et al. (2016). Exosomes from bulk and stem cells from human prostate cancer have a differential microRNA content that contributes cooperatively over local and pre-metastatic niche. Oncotarget 7 (4), 3993-4008. doi: 10.18632/oncotarget.6540

Song, X., Ding, Y., Liu, G., Yang, X., Zhao, R., Zhang, Y., et al. (2016). Cancer Cellderived Exosomes Induce Mitogen-activated Protein Kinase-dependent Monocyte Survival by Transport of Functional Receptor Tyrosine Kinases. J. Biol. Chem. 291 (16), 8453-8464. doi: 10.1074/jbc.M116.716316

Sreepadmanabh, M., and Toley, B. J. (2018). Investigations into the cancer stem cell niche using in-vitro 3-D tumor models and microfluidics. Biotechnol. Adv. 36 (4), 1094-1110. doi: 10.1016/j.biotechadv.2018.03.009

Sun, X., Ma, X., Wang, J., Zhao, Y., Wang, Y., Bihl, J. C., et al. (2017). Glioma stem cells-derived exosomes promote the angiogenic ability of endothelial cells through miR-21/VEGF signal. Oncotarget 8 (22), 36137-36148. doi: 10.18632/ oncotarget.16661

Sun, Z. P., Li, A. Q., Jia, W. H., Ye, S., Van Eps, G., Yu, J. M., et al. (2017). MicroRNA expression profiling in exosomes derived from gastric cancer stemlike cells. Oncotarget 8 (55), 93839-93855. doi: 10.18632/oncotarget.21288

Sun, Z., Wang, L., Dong, L., and Wang, X. (2018). Emerging role of exosome signalling in maintaining cancer stem cell dynamic equilibrium. J. Cell Mol. Med. 22 (8), 3719-3728. doi: 10.1111/jcmm.13676

Syn, N., Wang, L., Sethi, G., Thiery, J. P., and Goh, B. C. (2016). ExosomeMediated Metastasis: From Epithelial-Mesenchymal Transition to Escape from
Immunosurveillance. Trends Pharmacol. Sci. 37 (7), 606-617. doi: 10.1016/ j.tips.2016.04.006

Thery, C., Witwer, K. W., Aikawa, E., Alcaraz, M. J., Anderson, J. D., Andriantsitohaina, R., et al. (2018). Minimal information for studies of extracellular vesicles 2018 (MISEV2018): a position statement of the International Society for Extracellular Vesicles and update of the MISEV2014 guidelines. J. Extracell Vesicles 7 (1), 1535750. doi: 10.1080/ 20013078.2018.1535750

Trams, E. G., Lauter, C. J., Salem, J. N., and Heine, U. (1981). Exfoliation of membrane ecto-enzymes in the form of micro-vesicles. Biochim. Biophys. Acta 645 (1), 63-70. doi: 10.1016/0005-2736(81)90512-5

Wang, L., Yang, G., Zhao, D., Wang, J., Bai, Y., Peng, Q., et al. (2019). CD103positive CSC exosome promotes EMT of clear cell renal cell carcinoma: role of remote MiR-19b-3p. Mol. Cancer 18 (1), 86. doi: 10.1186/s12943-019-0997-z

Webber, J. P., Spary, L. K., Sanders, A. J., Chowdhury, R., Jiang, W. G., Steadman, R., et al. (2015). Differentiation of tumour-promoting stromal myofibroblasts by cancer exosomes. Oncogene 34 (3), 290-302. doi: 10.1038/onc.2013.560

Wortzel, I., Dror, S., Kenific, C. M., and Lyden, D. (2019). Exosome-Mediated Metastasis: Communication from a Distance. Dev. Cell 49 (3), 347-360. doi: 10.1016/j.devcel.2019.04.011

Xiao, D., Barry, S., Kmetz, D., Egger, M., Pan, J., Rai, S. N., et al. (2016). Melanoma cell-derived exosomes promote epithelial-mesenchymal transition in primary melanocytes through paracrine/autocrine signaling in the tumor microenvironment. Cancer Lett. 376 (2), 318-327. doi: 10.1016/ j.canlet.2016.03.050

Yi, H., Ye, J., Yang, X. M., Zhang, L. W., Zhang, Z. G., and Chen, Y. P. (2015). High-grade ovarian cancer secreting effective exosomes in tumor angiogenesis. Int. J. Clin. Exp. Pathol. 8 (5), 5062-5070.

Yukawa, H., Suzuki, K., Aoki, K., Arimoto, T., Yasui, T., Kaji, N., et al. (2018). Imaging of angiogenesis of human umbilical vein endothelial cells by uptake of exosomes secreted from hepatocellular carcinoma cells. Sci. Rep. 8 (1), 6765. doi: 10.1038/s41598-018-24563-0

Zhang, P., Zhou, H., Lu, K., Lu, Y., Wang, Y., and Feng, T. (2018). Exosomemediated delivery of MALAT1 induces cell proliferation in breast cancer. Onco Targets Ther. 11, 291-299. doi: 10.2147/OTT.S155134

Zou, L., Ma, X., Lin, S., Wu, B., Chen, Y., and Peng, C. (2019). Bone marrow mesenchymal stem cell-derived exosomes protect against myocardial infarction by promoting autophagy. Exp. Ther. Med. 18 (4), 2574-2582. doi: 10.3892/etm.2019.7874

Conflict of Interest: The authors declare that the research was conducted in the absence of any commercial or financial relationships that could be construed as a potential conflict of interest.

Copyright (C) 2020 Al-Sowayan, Al-Shareeda and Alrfaei. This is an open-access article distributed under the terms of the Creative Commons Attribution License (CC BY). The use, distribution or reproduction in other forums is permitted, provided the original author(s) and the copyright owner(s) are credited and that the original publication in this journal is cited, in accordance with accepted academic practice. No use, distribution or reproduction is permitted which does not comply with these terms 